\title{
Pten dependence distinguishes haematopoietic stem cells from leukaemia-initiating cells
}

\author{
Ömer H. Yilmaz ${ }^{1}$, Riccardo Valdez ${ }^{2}$, Brian K. Theisen ${ }^{2}$, Wei Guo ${ }^{3}$, David O. Ferguson ${ }^{2}$, Hong Wu $^{3}$ \\ $\&$ Sean J. Morrison ${ }^{1}$
}

Recent advances have highlighted extensive phenotypic and functional similarities between normal stem cells and cancer stem cells. This raises the question of whether disease therapies can be developed that eliminate cancer stem cells without eliminating normal stem cells. Here we address this issue by conditionally deleting the Pten tumour suppressor gene in adult haematopoietic cells. This led to myeloproliferative disease within days and transplantable leukaemias within weeks. Pten deletion also promoted haematopoietic stem cell (HSC) proliferation. However, this led to HSC depletion via a cell-autonomous mechanism, preventing these cells from stably reconstituting irradiated mice. In contrast to leukaemia-initiating cells, HSCs were therefore unable to maintain themselves without Pten. These effects were mostly mediated by mTOR as they were inhibited by rapamycin. Rapamycin not only depleted leukaemia-initiating cells but also restored normal HSC function. Mechanistic differences between normal stem cells and cancer stem cells can thus be targeted to deplete cancer stem cells without damaging normal stem cells.

Cancer stem cells have notable phenotypic and mechanistic similarities to normal stem cells in the same tissues ${ }^{1-4}$. Acute myeloid leukaemia (AML) is sustained by leukaemic stem cells that are also called leukaemia-initiating cells because they are defined by their ability to transfer disease on transplantation into irradiated mice $e^{5-7}$. Leukaemia-initiating cells express markers similar to normal HSCs ${ }^{5,6}$ and depend on similar mechanisms to self-renew ${ }^{8,9}$. Brain cancer stem cells also express markers of normal neural stem cells and depend on similar pathways for their proliferation ${ }^{4,10}$. The Hedgehog, Wnt and Notch pathways that often promote cancer cell proliferation also promote normal stem cell self-renewal ${ }^{1,2,11,12}$. Conversely, tumour suppressors that inhibit cancer cell proliferation-such as p53, p16 ${ }^{1 \mathrm{NK} 4 a}$ and $19^{\mathrm{ARF}}$-also inhibit stem cell self-renewal ${ }^{11,13,14}$. Whether cancer stem cells arise from normal stem cells or other cells, their similarity to normal stem cells indicates that they inherit or acquire stem cell properties. This raises the question of whether it will be possible to identify therapies that eliminate cancer stem cells without eliminating normal stem cells in the same tissues.

We have addressed this issue by examining the effect of Pten deletion on leukaemia-initiating cells and normal HSCs. PTEN (for phosphatase and tensin homologue) is a phosphatase that negatively regulates signalling through the phosphatidylinositol-3-OH kinase $(\mathrm{PI}(3) \mathrm{K})$ pathway, inhibiting proliferation and survival ${ }^{15,16}$. Pten is commonly deleted or otherwise inactivated in diverse cancers ${ }^{17}$, including haematopoietic malignancies ${ }^{18-21}$. Here we report that whereas Pten deletion causes the generation of transplantable leukaemia-initiating cells, it also causes the depletion of normal HSCs, thus identifying a mechanistic difference between the maintenance of normal stem cells and cancer stem cells.

\section{Pten deletion leads to leukaemogenesis}

Pten was conditionally deleted from 6-to-8-week-old Pten ${ }^{\text {flffl }}$; Mx-1Cre mice by administering seven doses of polyinosine-polycytidine (pIpC) over 14 days to induce Cre expression ${ }^{22,23}$. After 14 days, Pten seemed to be completely deleted from HSCs and other haematopoietic cells (Supplementary Fig. 1). We analysed Pten ${ }^{\text {flffl }} ; \mathrm{Mx}$-1-Cre mice, as well as Pten ${ }^{f l /+} ; M x-1-C r e$ littermate control mice, five days after pIpC treatment. Almost all Pten ${ }^{\text {fllfl }}$; Mx-1-Cre mice (17 out of 19) developed myeloproliferative disease marked by a tenfold increase in spleen cellularity (Fig. 1c), complete histological effacement of the splenic architecture (Fig. 1b), reduced bone marrow cellularity (Fig. 1c), and increased blast cell frequency (Fig. 1d). The increased spleen cellularity was largely attributable to extramedullary haematopoiesis (Supplementary Fig. 2c, d) with a prominent expansion in the number of immature myeloid cells (Supplementary Fig. 2e-g; Supplementary Table 1). None out of $20 \mathrm{Pten}^{f l /+} ; \mathrm{Mx}$-1-Cre littermates showed these changes after pIpC treatment (Fig. 1c, a, d).

Within 4 to 6 weeks after pIpC treatment, most Pten $^{\text {fllfl }}$; Mx-1-Cre mice progressed to frank leukaemia ${ }^{24}$, including AML and acute lymphoblastic leukaemia (ALL), and died (for the criteria used to diagnose leukaemias, see Supplementary Table 2). AMLs were characterized by large numbers of chloroacetate-esterase-positive myeloid blasts in the spleen (Fig. 1e), and ALLs were characterized by large numbers of terminal deoxynucleotidyl transferase (TdT)positive lymphoid blasts throughout the thymus, which was also enlarged and effaced (Fig. 1f). The bone marrow contained $\mathrm{Mac}-1^{+} \mathrm{Gr}-1^{\text {low }} \mathrm{CD}^{-}$myeloid blasts and $\mathrm{CD} 4^{+} \mathrm{CD} 8^{+} \mathrm{CD} 3^{+} \mathrm{Mac}-$ $1^{-}$lymphoid blasts (Fig. 1h, i; data not shown). Karyotypic analysis of myeloid blasts from four Pten-deleted mice with AML revealed 
marked aneuploidy and/or chromosomal translocations, suggesting leukaemogenesis was associated with additional mutations after Pten deletion (Supplementary Fig. 3). Common abnormalities across multiple karyotypes from each mouse suggested that the AMLs were clonal or oligoclonal (Supplementary Fig. 3).

\section{HSCs proliferate after Pten deletion but become depleted}

We examined the cell cycle status of whole bone marrow cells and Flk-2 ${ }^{-} \mathrm{Sca}-1^{+} \mathrm{Lin}^{-} \mathrm{c}-\mathrm{Kit}^{+} \mathrm{CD} 48^{-}$cells five days after completing pIpC administration. Flk- $2^{-} \mathrm{Sca}-1^{+} \mathrm{Lin}^{-} \mathrm{c}-\mathrm{Kit}^{+} \mathrm{CD} 48^{-}$cells are highly enriched for $\mathrm{HSCs}^{25-27}$, representing only $0.005 \%$ of bone marrow cells. Nineteen out of 20 mice transplanted with 15 Flk$2^{-} \mathrm{Sca}-1^{+} \mathrm{Lin}^{-} \mathrm{c}-\mathrm{Kit}^{+} \mathrm{CD} 48^{-}$cells from control mice showed long- term multilineage reconstitution by the donor cells (Supplementary Table 3). There was no significant effect of Pten deletion on the cell cycle distribution of whole bone marrow cells (Fig. 2a, b). In contrast, there was a three-to-four-fold increase in the percentage of dividing Flk- ${ }^{-} \mathrm{Sca}-1^{+} \mathrm{Lin}^{-} \mathrm{c}-\mathrm{Kit}^{+} \mathrm{CD} 48^{-}$cells, and in the percentage that incorporated the nucleotide analogue $\mathrm{BrdU}$ (5-bromodeoxyuridine) over a 19-h period (Fig. 2c-f). These data suggest that Pten promotes quiescence in HSCs, and that in the absence of Pten HSCs are driven into cycle.

Consistent with this, the absolute number of Flk-2 ${ }^{-} \mathrm{Sca}-1^{+} \mathrm{Lin}{ }^{-} \mathrm{c}-$ $\mathrm{Kit}^{+} \mathrm{CD} 48^{-}$cells per Pten ${ }^{\text {flffl }}$; Mx-1-Cre mouse increased by approximately threefold within five days of pIpC treatment (Fig. 2g; see Methods for details). Notably, when Pten ${ }^{f l f f} ; M x-1$-Cre mice were
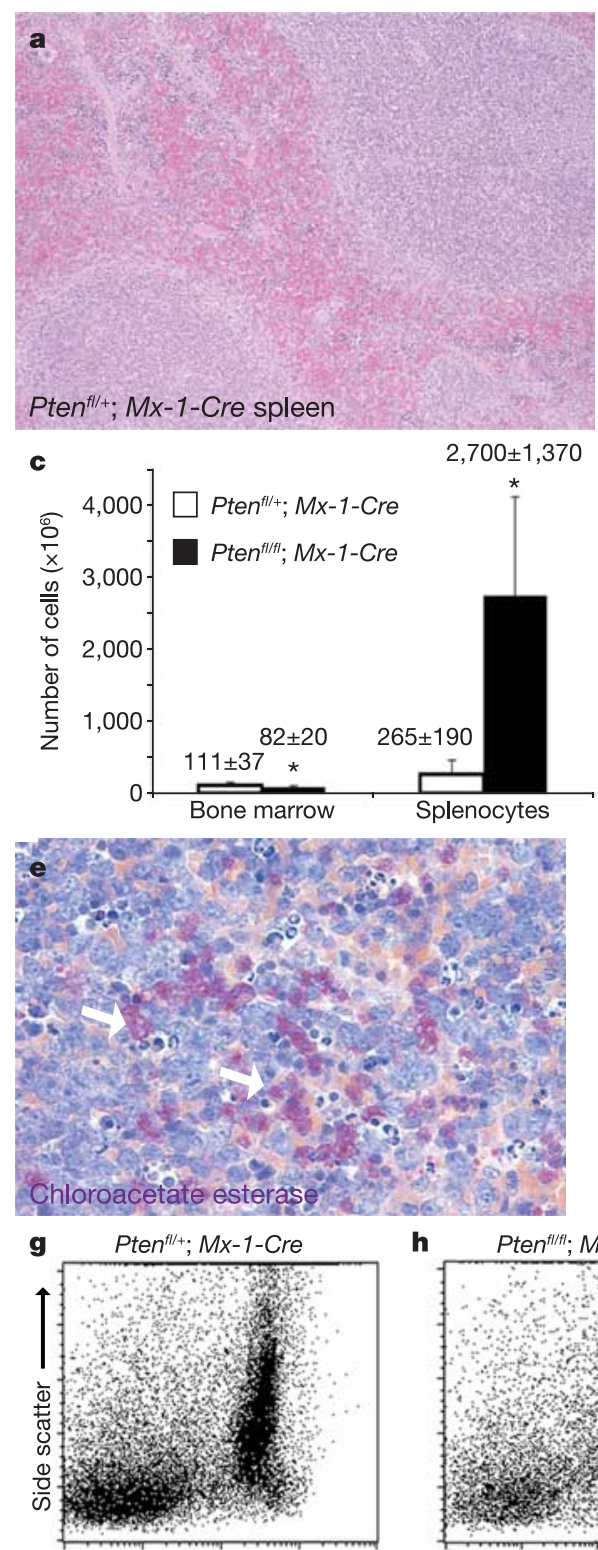

CD45

h $\quad$ Pten $^{f / / f l} ; M x-1-C r e$

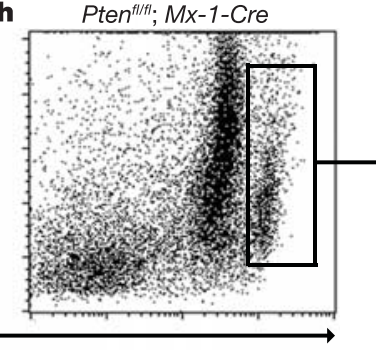

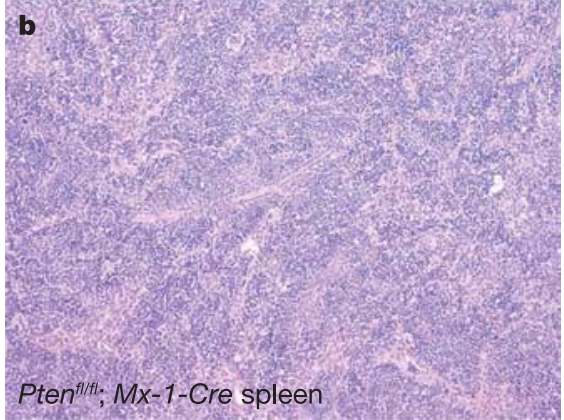
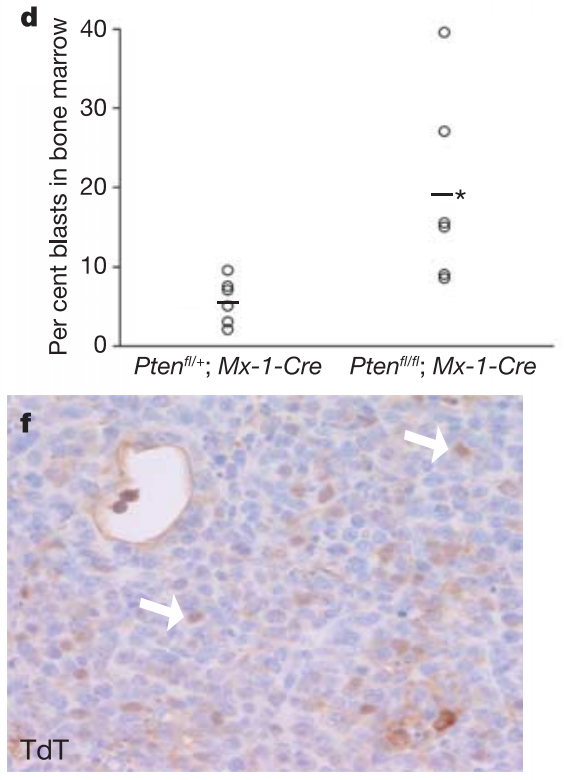

i

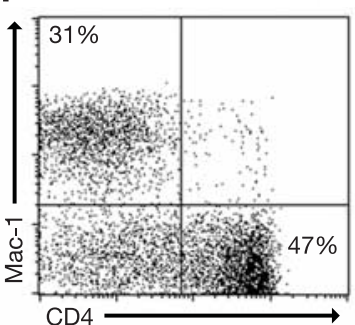

Figure 1 | Pten deletion from adult haematopoietic cells leads to myeloproliferative disease that progresses to AML and ALL. a-c, Within five days of Pten deletion, Pten ${ }^{\text {fllfl }}$; Mx-1-Cre mice developed myeloproliferative disease marked by increased spleen cellularity (c), reduced bone marrow cellularity (c), and complete effacement of the splenic architecture (compare $\mathbf{b}$ with $\mathbf{a}$ ) owing to myeloid-predominant extramedullary haematopoiesis (Supplementary Fig. 2). Values are mean \pm s.d. ${ }^{*}, P<0.05$. d, Blast cell frequency was significantly increased in Pten $^{f l / f l}$; Mx-1-Cre mice, but five days after pIpC treatment only a minority of these mice ( 2 out of 6 ) showed more than $20 \%$ blasts. Bars indicate mean values. ${ }^{*}, P<0.01$. e, $\mathbf{f}, \mathrm{By}$ six weeks after pIpC treatment, most Pten $^{\text {fl } l f l}$; Mx-1-Cre mice had greater than $20 \%$ blast cells in the bone marrow, were acutely ill, and showed the pathological features of both AML

(e; mononuclear blasts in the spleen; white arrows) and ALL (f; TdT-positive lymphoid blasts in the thymus; white arrows). $g-\mathbf{i}$, The bone marrow of Pten $^{\text {flffl }}$; Mx-1-Cre mice contained a blast cell population (box in $\mathbf{h}$ ), with myeloid (i; Mac-1-positive) and lymphoid (i; CD4-positive) cells, not evident in control mice $(\mathbf{g})$. 
examined 24 to 39 days after pIpC treatment, the number of Flk- ${ }^{-} \mathrm{Sca}-1^{+} \mathrm{Lin}^{-} \mathrm{c}-\mathrm{Kit}^{+} \mathrm{CD} 48^{-}$cells declined significantly below that found in control mice (Fig. 2g). This suggested that HSCs transiently expanded in number after Pten deletion, but were unable to maintain themselves and subsequently became depleted.

To test the function of Pten-deficient HSCs, we transplanted 15 Flk-2 ${ }^{-} \mathrm{Sca}-1^{+} \mathrm{Lin}^{-} \mathrm{c}-\mathrm{Kit}^{+} \mathrm{CD} 48^{-}$donor cells from $\mathrm{Pten}^{f l / f l} ; \mathrm{Mx}-1$-Cre mice or littermate controls (five days after pIpC) into irradiated recipient mice along with 200,000 recipient bone marrow cells (Fig. 2h). Whereas control cells gave high levels of long-term multilineage reconstitution in all five recipients, Pten-deficient cells initially gave multilineage reconstitution, but by eight weeks after transplantation none of the seven recipients remained multilineagereconstituted. None of these recipients developed AML or ALL. Small numbers of Pten-deficient HSCs were thus capable of efficiently engrafting and undergoing multilineage differentiation but became depleted over time and gave only transient, rather than long-term, multilineage reconstitution. In four independent experiments, a total of 23 mice that were injected with 15 Flk-2 ${ }^{-} \mathrm{Sca}-1^{+} \mathrm{Lin}^{-} \mathrm{c}-$ $\mathrm{Kit}^{+} \mathrm{CD} 48^{-}$cells from Pten ${ }^{\text {fl/fl }} ; \mathrm{Mx}$-1-Cre donors did not develop leukaemia. Eighteen of these mice showed transient multilineage reconstitution whereas only two remained long-term multilineagereconstituted, and levels of reconstitution declined continuously in both of these mice (Supplementary Table 3). The fact that donor chimaerism consistently declined over time, even in mice that did not develop leukaemia, demonstrates that the depletion of Pten-deficient HSCs is not caused by leukaemogenesis.

We performed similar experiments with whole bone marrow cells. Whereas all recipients of control bone marrow cells showed longterm multilineage reconstitution (Fig. 2i) with high levels of donor cells (Fig. 2j), the percentage of recipients that were multilineagereconstituted by $\mathrm{Pten}^{\text {fllfl }}$; Mx-1-Cre cells, and the levels of reconstitution in these recipients, declined over time. The results with whole bone marrow rule out the possibility that Pten-deficient HSCs simply changed their surface-marker phenotype. Moreover, only 3 out of 10 recipients of Pten $^{\text {fl/fl }}$; Mx-1-Cre bone marrow cells developed AML or ALL, further demonstrating that the loss of HSC activity was not secondary to leukaemogenesis.

\section{Pten acts cell-autonomously to maintain HSCs}

The possibility remained that a few days of exposure to the myeloproliferative disease in donor mice might have irreversibly damaged the Pten-deficient HSCs before transplantation. To test whether the depletion of HSCs in Pten ${ }^{\text {flffl }}$; Mx-1-Cre mice was an indirect consequence of neoplasms/altered haematopoietic environment, or whether Pten is required cell-autonomously for the maintenance of

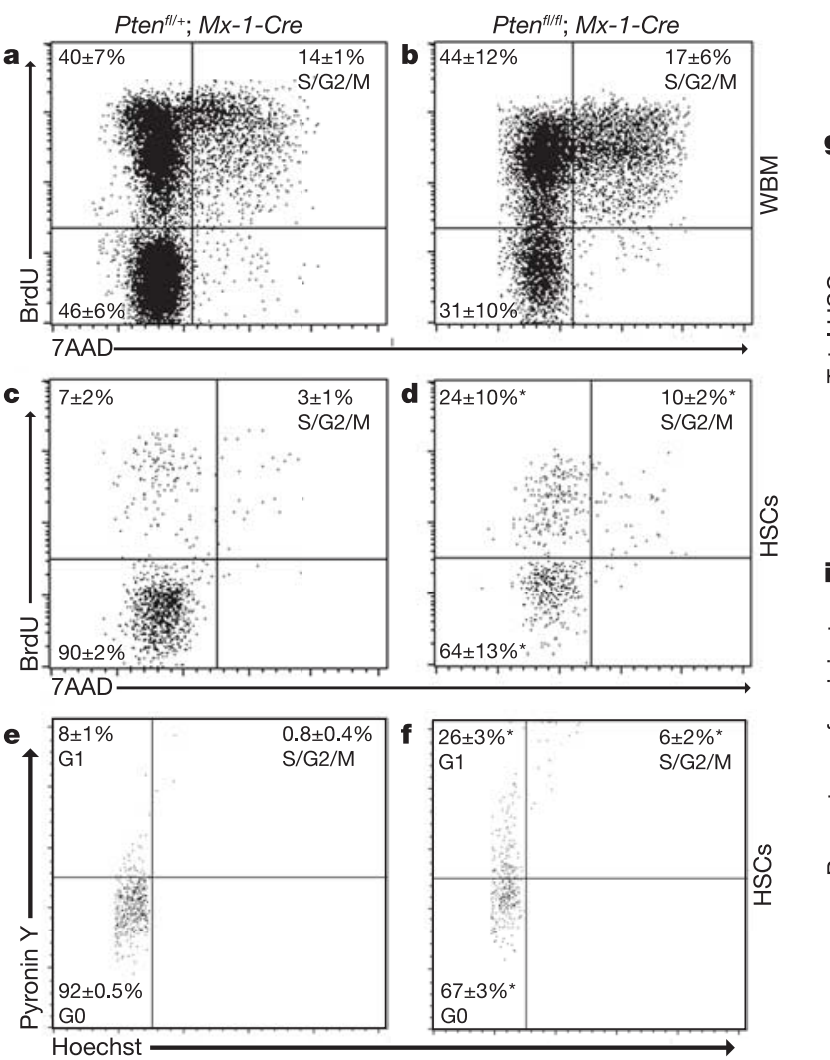

Figure 2 | HSCs proliferate after Pten deletion, transiently expanding in number before becoming depleted. a, b, No significant difference in the cell cycle status of whole bone marrow (WBM) cells from Pten $^{\text {fl/ff }} ; M x-1-C r e$ mice (b) and littermate controls (a) was observed five days after pIpC treatment. BrdU was administered for $19 \mathrm{~h}$ to mark cells that entered $\mathrm{S}$ phase, and 7-amino-actinomycin D (7-AAD) indicated DNA content. Values are mean \pm s.d. of three experiments. c, d, Flk- $2^{-}$Sca- $1^{+} \mathrm{Lin}^{-}$c-Kit ${ }^{+} \mathrm{CD} 48$ HSCs from Pten $^{f l / f l} ; M x-1$-Cre mice (d) included significantly $\left({ }^{\star}, P<0.05\right)$ more dividing cells relative to controls $(\mathbf{c})$. Values are mean \pm s.d. of three experiments. e, $\mathbf{f}$, Significantly $\left({ }^{*}, P<0.01\right)$ fewer Flk- ${ }^{-}$Sca- $1^{+}$Lin $^{-} \mathrm{c}-\mathrm{Kit}^{+} \mathrm{CD} 48^{-}$cells from $\mathrm{Pten}^{\text {fl/ff }} ; \mathrm{Mx}$-1-Cre mice (f) were in G0 compared with controls (e) on the basis of Hoechst/Pyronin Y staining of DNA/RNA content. Values are mean \pm s.d. of three experiments. $g$, Total number of Flk-2 ${ }^{-}$Sca- $1^{+}$Lin $^{-} \mathrm{c}-\mathrm{Kit}^{+} \mathrm{CD} 48^{-}$cells in Pten ${ }^{\text {flffl }} ; \mathrm{Mx}$-1-Cre mice
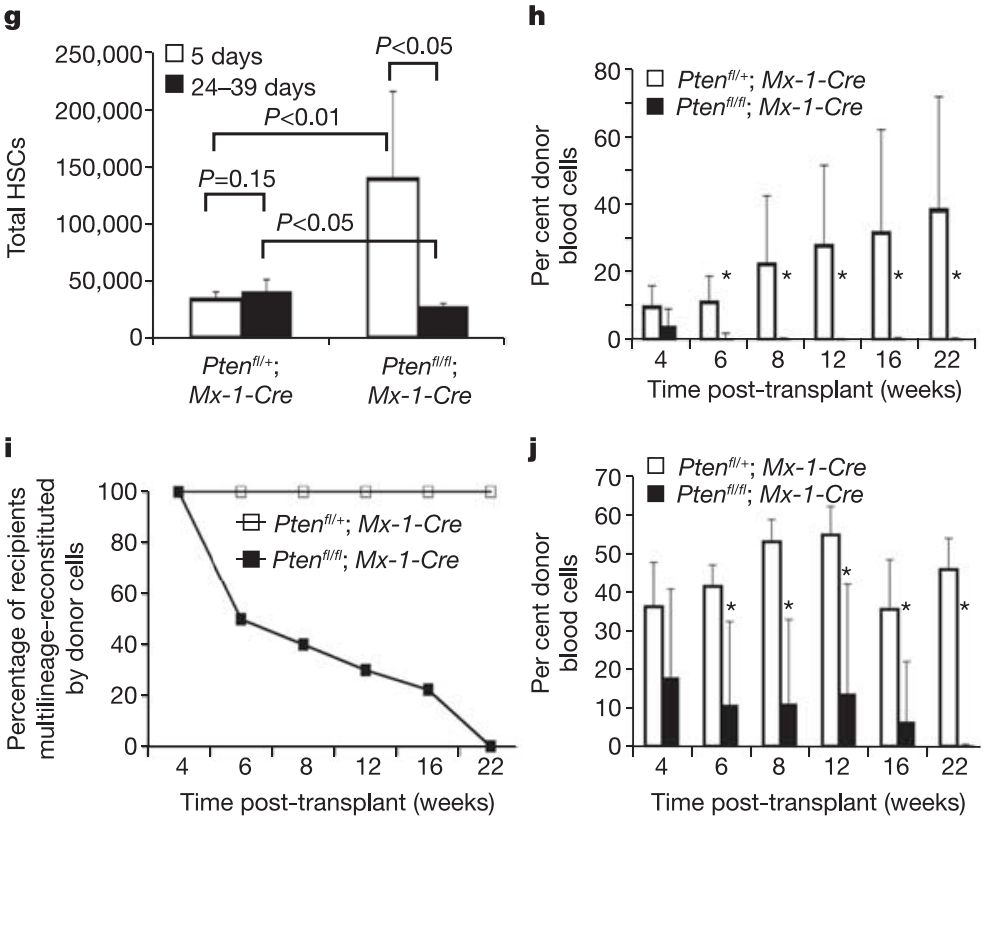

was significantly increased relative to littermate controls five days after pIpC treatment, but significantly decreased relative to controls 24 to 39 days after $\mathrm{pIpC}$ administration. Values are mean \pm s.d. of six experiments. $\mathbf{h}$, Fifteen donor Flk- ${ }^{-} \mathrm{Sca}^{+}{ }^{+} \mathrm{Lin}^{-} \mathrm{c}_{\mathrm{Cit}}{ }^{+} \mathrm{CD} 48^{-}$cells from Pten ${ }^{\text {flffl }} ; \mathrm{Mx}$-1-Cre mice or controls were transplanted into irradiated recipients along with 200,000 recipient bone marrow cells. Whereas control cells gave long-term multilineage reconstitution in all recipients $(n=5)$, Pten-deficient cells gave only transient multilineage reconstitution $\left(n=7\right.$; $\left.^{\star}, P<0.05\right)$ $\mathbf{i}, \mathbf{j}$, Similar results were observed when 300,000 bone marrow cells from Pten $^{f l f f} ; M x-1-C r e$ mice or controls were transplanted into irradiated recipients $\left(n=10\right.$ and 4 , respectively; $\left.{ }^{*}, P<0.05\right)$ along with 300,000 recipient bone marrow cells. In $\mathbf{h}$ and $\mathbf{j}$, error bars represent standard deviation. 
HSCs, we transplanted Pten ${ }^{f l f l}$; Mx-1-Cre bone marrow cells or control bone marrow cells (both $\mathrm{CD} 45.2^{+}$) into recipient mice $\left(\mathrm{CD} 45.1^{+}\right)$along with half as many recipient bone marrow cells (Fig. 3a). Six weeks after transplantation, when these mice showed stable chimaerism, Pten was deleted and the relative frequencies of donor and recipient HSCs were monitored over time. As expected, two days after pIpC treatment donor cells accounted for roughly twothirds of HSCs in the bone marrow irrespective of whether they were from control (Fig. 3b) or Pten-deficient (Fig. 3c) mice.
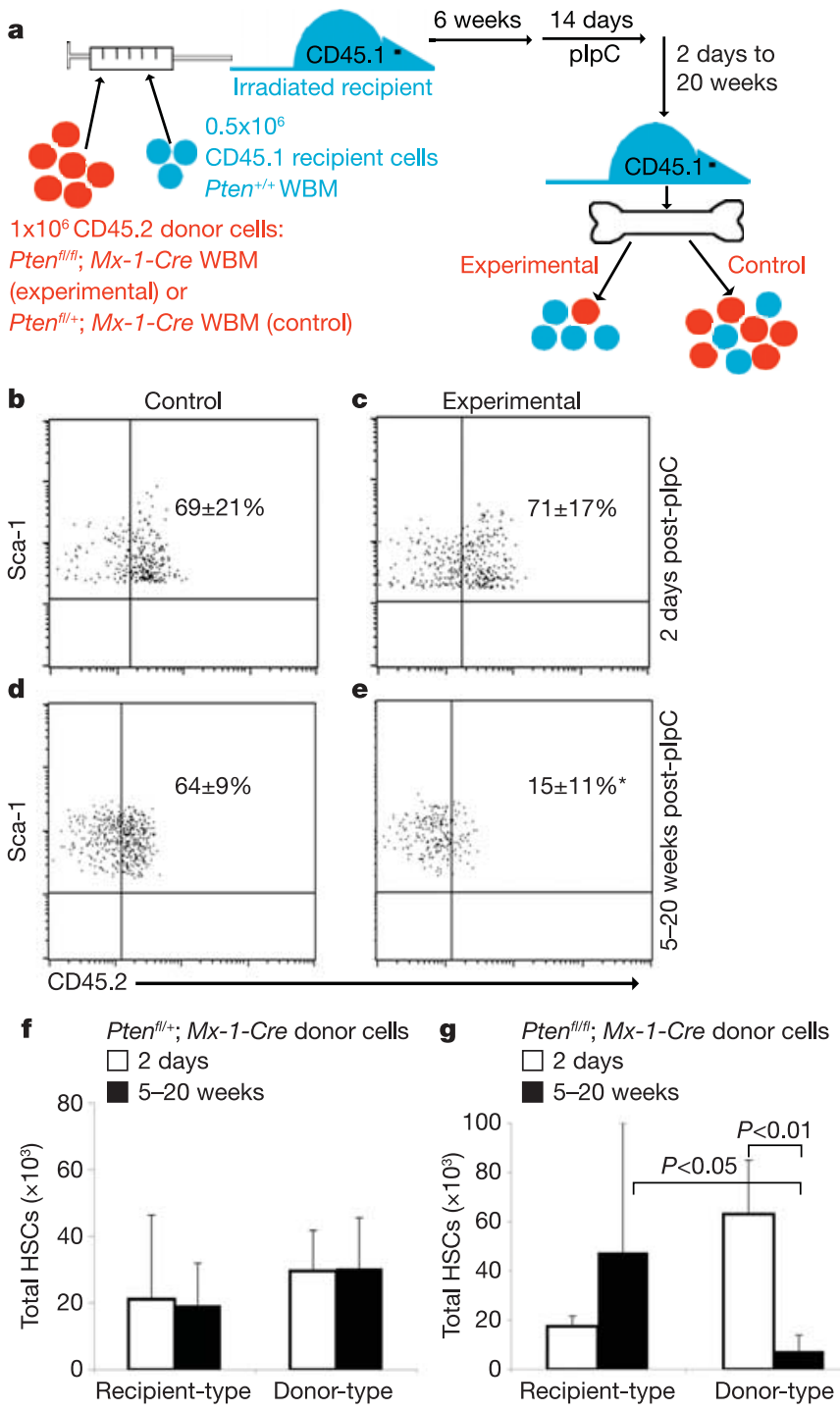

Figure 3 Pten is required cell-autonomously for HSC maintenance. a, Irradiated (CD45.1) recipients were transplanted with a 2:1 ratio of donor (CD45.2) Pten ${ }^{f l f l}$; Mx-1-Cre bone marrow cells (experimental treatment), or control bone marrow cells (control treatment), to recipient bone marrow cells. Six weeks after transplantation, Pten was deleted.

b, c, Two days after pIpC treatment, donor cells accounted for 69 to $71 \%$ of Flk- ${ }^{-} \mathrm{Sca}-1^{+} \mathrm{Lin}^{-} \mathrm{c}-\mathrm{Kit}^{+} \mathrm{CD} 48^{-}$HSCs in recipient mice as expected, whether the mice had been transplanted with control $\left(\right.$ Pten $\left.^{f l+} ; \mathrm{Mx}-1-\mathrm{Cre}\right)$ donor cells (b) or Pten ${ }^{f l / f l} ; M x$-1-Cre donor cells (c). Values are mean \pm s.d. of three mice per treatment. d, e, Subsequently, 5 to 20 weeks after pIpC treatment, control cells still accounted for $64 \%$ of bone marrow Flk-2 ${ }^{-}$Sca- $1^{+} \mathrm{Lin}^{-}$c-Kit ${ }^{+} \mathrm{CD} 48^{-}$HSCs (d), but Pten $^{\text {fllfl }} ; M x$-1-Cre donor cells accounted for only $15 \%$ of Flk- $2^{-} \mathrm{Sca}^{-}{ }^{+} \mathrm{Lin}^{-} \mathrm{c}-\mathrm{Kit}^{+} \mathrm{CD} 48^{-}$HSCs (e). Values are mean \pm s.d. of ten mice per treatment. ${ }^{*}, P<0.05$. f, $\mathbf{g}$, Control HSCs were stable over time (f), whereas Pten fl/ff; $M x-1$-Cre donor HSCs became depleted relative to recipient (wild-type) HSCs in the same mice (g). Values are mean \pm s.d.
Consistent with a cell-autonomous requirement for Pten in HSCs, the number of Pten-deficient HSCs declined over time and the number of wild-type recipient HSCs in the same mice increased. By 5 to 20 weeks after pIpC administration, control Pten ${ }^{f l /+} ; \mathrm{Mx}-1-\mathrm{Cre}$ donor cells still accounted for $64 \%$ of bone marrow Flk- $2^{-}$Sca$1^{+}$Lin $^{-} \mathrm{c}-\mathrm{Kit}^{+} \mathrm{CD} 48^{-}$cells (Fig. 3d), but Pten ${ }^{\text {fllfl }} ; \mathrm{Mx}$-1-Cre donor cells accounted for only $15 \%$ of bone marrow Flk-2 ${ }^{-} \mathrm{Sca}-1^{+} \mathrm{Lin}^{-} \mathrm{c}-$ $\mathrm{Kit}^{+} \mathrm{CD} 48^{-}$cells (Fig. 3e). The total number of control Pten ${ }^{f l /+} ; \mathrm{Mx}-$ 1-Cre donor HSCs was stable over time (Fig. 3f). In contrast, Pten ${ }^{\text {flffl; }}$; Mx-1-Cre donor HSCs initially dominated the HSC pool, but by 5 to 20 weeks after pIpC treatment recipient HSCs outnumbered Ptendeficient donor HSCs by 6.4-fold (Fig. 3g). To confirm functionally the depletion of donor HSCs, we transplanted $1 \times 10^{6}$ bone marrow cells, or $100 \mathrm{Flk}-2^{-} \mathrm{Sca}-1^{+} \mathrm{Lin}^{-} \mathrm{c}-\mathrm{Kit}^{+} \mathrm{CD} 48^{-}$cells, into irradiated mice. All recipients of bone marrow cells from control mice (from Fig. 3d) showed long-term multilineage reconstitution by donor cells (Supplementary Table 4). However, recipients of Pten-deficient donor (from Fig. 3e) bone marrow cells or Flk-2 ${ }^{-} \mathrm{Sca}-1^{+} \mathrm{Lin}^{-} \mathrm{c}-$ $\mathrm{Kit}^{+} \mathrm{CD} 48^{-}$cells never achieved multilineage donor cell reconstitution (Supplementary Table 4). As Pten-deficient HSCs were depleted and control HSCs were expanded within the same mice, these data confirm that Pten is required cell-autonomously for the maintenance of HSCs.

Pten deletion seemed to deplete HSCs by inhibiting self-renewal rather than by promoting cell death. We did not detect any increase in cell death, as assessed by staining for annexin Vor activated caspase-3, in either whole bone marrow cells or Flk-2 ${ }^{-} \mathrm{Sca}-1^{+} \mathrm{Lin}^{-} \mathrm{c}-\mathrm{Kit}^{+} \mathrm{CD} 48^{-}$ cells from $\mathrm{Pten}^{\text {fllfl }}$; Mx-1-Cre mice four weeks after $\mathrm{pIpC}$ treatment (Supplementary Fig. 4). Moreover, approximately 90\% of single Flk-2 ${ }^{-} \mathrm{Sca}-1^{+} \mathrm{Lin}^{-} \mathrm{c}-\mathrm{Kit}^{+} \mathrm{CD} 48^{-}$cells from either Pten-deleted mice or control mice formed colonies in methylcellulose irrespective of whether they were isolated five days or four weeks after pIpC treatment (Supplementary Fig. 5). If HSCs were destined to undergo cell death or rapid terminal differentiation after Pten deletion, then Flk- ${ }^{-}$Sca- $1^{+} \mathrm{Lin}^{-} \mathrm{c}-\mathrm{Kit}^{+} \mathrm{CD} 48^{-}$cells from Pten-deleted mice should have formed fewer colonies in methylcellulose. Together with the ability of Pten-deficient HSCs to efficiently engraft and transiently reconstitute irradiated mice (Fig. 2), these data suggest that HSCs show less self-renewal potential after Pten deletion.

\section{Pten-deficient leukaemias are transplantable}

Leukaemia-initiating cells are defined by their ability to transfer disease upon transplantation into irradiated mice ${ }^{5-7}$. These cells are rare among unfractionated leukaemia cells but are highly enriched among cells that express HSC markers ${ }^{5-7}$. To test whether the neoplasms in Pten ${ }^{\text {flffl }}$; Mx-1-Cre mice were transplantable, we transplanted bone marrow cells, splenocytes, Flk-2 ${ }^{-} \mathrm{Sca}-1^{+} \mathrm{Lin}^{-} \mathrm{c}-$ $\mathrm{Kit}^{+} \mathrm{CD} 48^{-}$cells $^{25-27}, \mathrm{Mac}-1^{+} \mathrm{CD} 4^{-} \mathrm{CD} 45^{\text {hi }}$ myeloid blasts, $\mathrm{Mac}-1^{+} \mathrm{B} 220^{-} \mathrm{CD} 3^{-}$myeloid cells, $\mathrm{CD} 4^{+} \mathrm{Mac}^{-}{ }^{-} \mathrm{CD} 45^{\mathrm{hi}}$ lymphoid blasts, or $\mathrm{CD}^{+} \mathrm{Mac}^{-}{ }^{-} / \mathrm{B} 220^{+} \mathrm{Mac}-1^{-}$lymphoid cells from five independent Pten ${ }^{\text {flflf }}$; Mx-1-Cre donors (which were euthanized owing to illness) into irradiated recipients. Virtually every recipient of $5 \times 10^{5}$ to $2 \times 10^{6}$ Pten $^{\text {flffl }}$; Mx-1-Cre donor bone marrow cells (Fig. 4a) or splenocytes (Fig. 4c) died within four weeks of transplantation with ALL and/or AML. Only a minority of the recipients of $3 \times 10^{5}$ Pten $^{\text {fllfl }}$; Mx-1-Cre donor bone marrow cells died, with 2 out of 14 developing AML and 2 out of 14 developing ALL (Fig. 4b). By limiting dilution statistics ${ }^{28}$, this suggests that approximately 1 out of every 600,000 bone marrow cells $(0.00017 \%)$ used in these experiments were capable of initiating AML or ALL. Recipients of control bone marrow cells $(n=20)$, splenocytes $(n=7)$ or HSCs $(n=17)$ from Pten $^{f l /+} ; M x-1$-Cre mice never developed leukaemia (data not shown).

To test whether leukaemia-initiating cells co-purify with HSCs, we transplanted 10 to $15 \mathrm{Flk}-2^{-} \mathrm{Sca}-1^{+} \mathrm{Lin}^{-} \mathrm{c}-\mathrm{Kit}^{+} \mathrm{CD} 48^{-}$cells from Pten $^{\text {flffl }} ;$ Mx-1-Cre donors into 33 irradiated recipients, five of which died from AML within four weeks (Fig. 4d). This suggests that 1 out 
of every 81 cells in this population (1.2\%) were capable of initiating $\mathrm{AML}^{28}$ - a considerable enrichment compared with whole bone marrow, although the vast majority of cells that co-purified with HSCs did not transfer disease.

Half of the recipients of 15,000 to 25,000 myeloid blasts died from AML within four weeks of transplantation (Fig. 4e), suggesting that 1 out of every $36,000(0.003 \%)$ myeloid blast cells initiated AML. Therefore, AML-initiating cells were enriched among blast cells when compared with whole bone marrow, but not nearly as enriched as among cells that expressed HSC markers. Recipients of bulk myeloid cells, lymphoid blasts and bulk lymphoid cells also developed ALL and/or AML, although leukaemia-initiating cells were not as enriched within these populations (Fig. $4 \mathrm{f}-\mathrm{h}$ ). Thus, a variety of cell populations contained leukaemia-initiating cells.

\section{Rapamycin depletes leukaemia-initiating cells}

The observation that Pten deletion leads to the depletion of normal HSCs but promotes the generation of leukaemia-initiating cells provided a rare distinction between the mechanisms that regulate the maintenance of normal stem cells compared with leukaemiainitiating cells. The $\mathrm{PI}(3) \mathrm{K}$ pathway is highly branched, but activates the mammalian target of rapamycin (mTOR) among other downstream effectors ${ }^{29,30}$. mTOR kinase activity is inhibited by the drug rapamycin ${ }^{31,32}$, and human AMLs and ALLs have been shown to respond to rapamycin ${ }^{33-35}$. Therefore, we administered rapamycin to Pten ${ }^{\text {flffl }}$; Mx-1-Cre mice to test whether it depleted leukaemiainitiating cells or rescued normal HSC function.

$\mathrm{Pten}^{\text {flffl }}$; Mx-1-Cre mice became overtly ill after pIpC treatment as they developed leukaemias, exhibiting lethargy, ruffling of fur, and hunched posture (Fig. 5a). All three such mice in this experiment died within 3 to 4 weeks of pIpC treatment from AML and ALL (Fig. 5c). In contrast, three mice that were maintained on daily injections of rapamycin ( $4 \mathrm{mg}$ per $\mathrm{kg}$ of body weight) remained healthy and active four weeks after pIpC treatment (Fig. 5b). These rapamycin-treated mice did not show any histological evidence of neoplasm, as the spleens had normal architecture with only focal areas of erythroid-predominant haematopoiesis (Fig. 5c). Daily injections of rapamycin for seven days after pIpC treatment also prevented the decrease in bone marrow cellularity (Fig. 5d) and the increase in spleen cellularity (Fig. 5e) observed in Pten fl/fl $; M x-1-C r e$ mice, without significantly affecting these parameters in control mice. Hence, mice maintained on rapamycin immediately after Pten deletion did not develop signs of haematopoietic malignancy.

To determine whether rapamycin eliminated leukaemia-initiating cells, we treated Pten-deleted mice with vehicle or rapamycin for six weeks and then transplanted graded doses of whole bone marrow cells into irradiated mice (which no longer received rapamycin). Recipients of bone marrow cells from vehicle-treated mice all died in a dose-dependent manner within 20 to 31 days of transplantation (Fig. 5f). In contrast, recipients of bone marrow cells from rapamycintreated mice remained healthy and never showed signs of leukaemia, irrespective of the dose of cells transplanted (Fig. 5f). This demonstrates that rapamycin inhibits the generation or maintenance of leukaemia-initiating cells.

To test whether rapamycin was effective against established leukaemias, mice that had been transplanted with Pten $^{\text {fl/fl }}$;Mx-1-Cre bone marrow cells were treated with daily injections of vehicle or rapamycin, beginning 15 weeks after pIpC administration. Although all three vehicle-treated mice died from ALL and/or AML within five weeks, all three rapamycin-treated mice remained overtly healthy (Supplementary Table 5). Almost all recipients of bone marrow cells from a vehicle-treated mouse died in a dose-dependent manner (Fig. 5g). In contrast, most recipients of bone marrow cells from rapamycin-treated mice survived (Fig. $5 \mathrm{~g}$ ). Thus, rapamycin reduced the frequency of leukaemia-initiating cells even when treatment was initiated after the onset of frank leukaemia. The two rapamycintreated mice that were not sacrificed to provide a source of cells for transplantation were treated with daily injections of rapamycin for 15 weeks. Although these mice seemed overtly healthy, with normalsized spleens and thymuses, one showed histological evidence of myeloproliferative disease and the other showed signs of AML and ALL.

Rapamycin treatment was also initiated after the transplantation of $2 \times 10^{6}$ bone marrow cells from a Pten-deficient mouse with AML and ALL into irradiated recipients. Vehicle-treated recipients all died
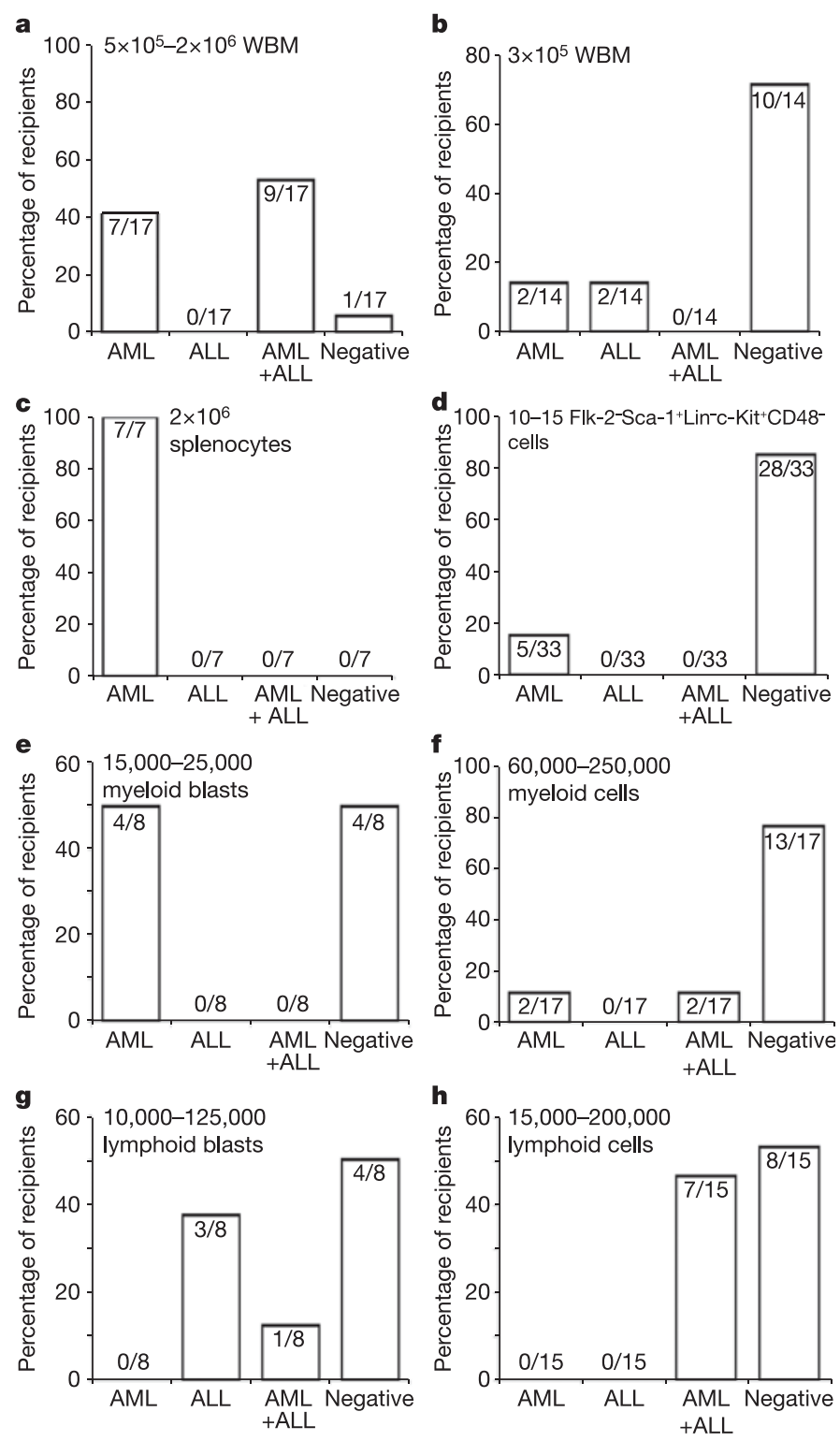

Figure 4 | AML- and ALL-initiating cells are rare in Pten-deleted mice, but are transplantable, are contained within multiple distinct populations, and are highly enriched among cells that express HSC markers.

$\mathbf{a}-\mathbf{h}$, Whole bone marrow (WBM) cells $(\mathbf{a}, \mathbf{b})$, whole splenocytes (c), Flk- ${ }^{-} \mathrm{Sca}^{+}{ }^{+} \mathrm{Lin}^{-} \mathrm{c}^{-\mathrm{Kit}^{+}}{ }^{+} \mathrm{CD} 48^{-} \mathrm{HSCs}^{25,26}$ (d), CD $45^{\mathrm{hi}} \mathrm{Mac}-1^{+} \mathrm{CD} 4{ }^{-}$ myeloid blasts (e), Mac- $1^{+}$B220 ${ }^{-} \mathrm{CD} 3^{-}$myeloid cells (f), $\mathrm{CD} 45^{\mathrm{hi}} \mathrm{CD} 4^{+} \mathrm{Mac}-$ $1^{-}$lymphoid blasts (g), or $\mathrm{CD}^{+} \mathrm{Mac}^{-} 1^{-} / \mathrm{B} 220^{+} \mathrm{Mac}-1^{-}$lymphoid cells (h) were transplanted into irradiated recipients from 3 to 5 independent Pten $^{\text {fllfl }} ;$ Mx-1-Cre donor mice with leukaemia. Donor $\left(\mathrm{CD} 45.2^{+}\right)$cells were competed against 200,000 recipient (CD45.1 +) bone marrow cells for radioprotection. Bars indicate the proportion of recipients that died with AML, ALL, or AML and ALL, or which survived with no signs of neoplasm ('Negative'). Recipients of Pten ${ }^{f l /+} ; M x-1$-Cre control bone marrow cells $(n=20)$, splenocytes $(n=7)$ or HSCs $(n=17)$ never developed leukaemia (data not shown). 
within 25 days of transplantation (Fig. 5h). In contrast, rapamycintreated recipients died 40 to 60 days after transplantation (Fig. $5 \mathrm{~h}$ ). When initiated after the onset of leukaemia, rapamycin was effective in prolonging the life of mice, but not in curing the leukaemias.

Rapamycin also inhibited the survival and proliferation of clonogenic leukaemia cells in culture. Freshly isolated or cultured myeloid blast cells from $P_{t e n}{ }^{f l / f l} ; M x$-1-Cre mice with AML were plated into methylcellulose. Rapamycin significantly reduced the percentage of blast cells that formed colonies, as well as colony size, in a dosedependent manner (Supplementary Fig. 6a-e). Rapamycin also significantly reduced the percentage of myeloid blasts in $S$ phase of the cell cycle, and increased the percentage of cells expressing activated caspase-3 (Supplementary Fig. 6f, g).

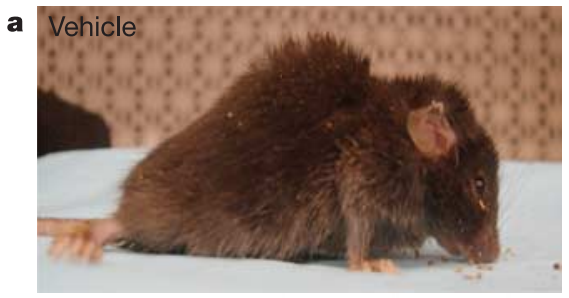

c
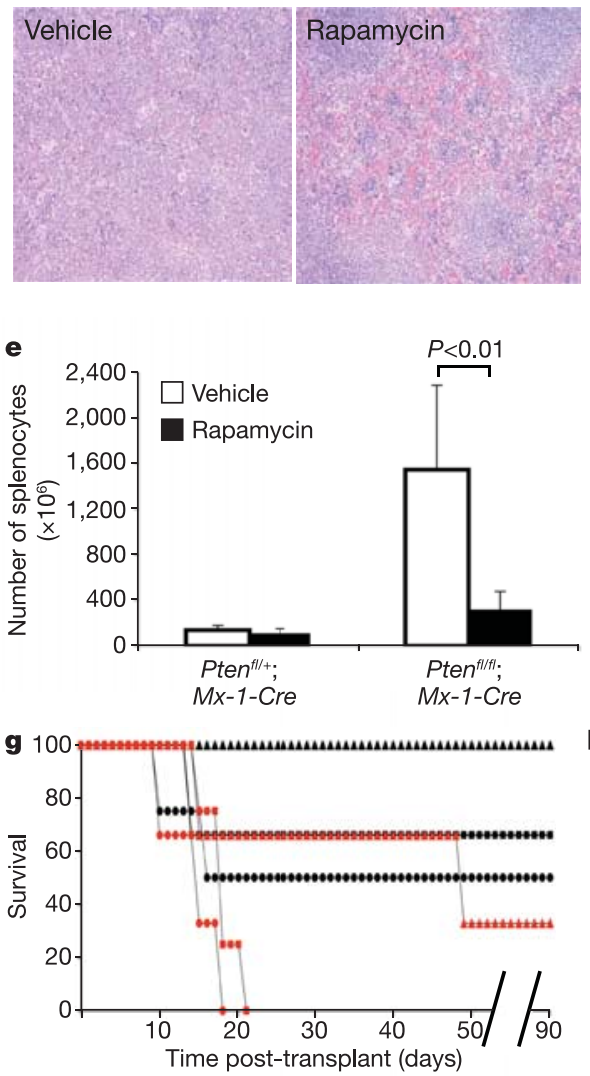

Figure 5 | Rapamycin depletes leukaemia-initiating cells. a, b, Four weeks after pIpC treatment, ten $^{f l / f l} ; M x-1$-Cre mice exhibited lethargy, ruffled fur, hunched posture, and required euthanization $(\mathbf{a} ; n=3)$, but if treated daily with $4 \mathrm{mg}$ per $\mathrm{kg}$ rapamycin remained healthy and active $(\mathbf{b} ; n=3)$.

c, Rapamycin-treated mice had normal spleen architecture (right panel), whereas vehicle-treated littermates developed AML and ALL (left panel). d, e, Rapamycin prevented the decrease in bone marrow cellularity (d) and the increase in spleen cellularity (e) in $\mathrm{Pten}^{\text {fl/fl }} ; \mathrm{Mx}$-1-Cre mice, but did not affect these parameters in controls. Values are mean \pm s.d. of 6 to 7 mice per treatment. f, Mice transplanted with $1 \times 10^{6} \mathrm{Pten}^{\mathrm{fl} / \mathrm{fl}} ; \mathrm{Mx}$-1-Cre donor (CD45.2) bone marrow cells along with $0.5 \times 10^{6}$ control (CD45.1) bone marrow cells were treated with vehicle or rapamycin ( $4 \mathrm{mg}$ per $\mathrm{kg}$ per day) for six weeks, starting immediately after pIpC treatment. Graded doses of

\section{Rapamycin rescues Pten-deficient HSCs}

Rapamycin also restored the capacity of Pten-deficient HSCs to provide long-term multilineage reconstitution to irradiated mice. Daily injections of rapamycin for seven days after $\mathrm{pIpC}$ administration did not affect the overall rate of proliferation in bone marrow, but did normalize the cell cycle distribution of Flk-2 ${ }^{-} \mathrm{Sca}-1^{+} \mathrm{Lin}{ }^{-} \mathrm{c}-$ $\mathrm{Kit}^{+} \mathrm{CD} 48^{-}$cells in Pten ${ }^{\text {fl/fl}}$; Mx-1-Cre mice without affecting the proliferation of HSCs from control littermates (Fig. 6a). Rapamycin also eliminated the HSC expansion observed seven days after pIpC treatment (Fig. 6b), and the HSC depletion observed after four weeks in Pten ${ }^{\text {flffl }}$; Mx-1-Cre mice (Fig. 6c), without affecting HSC numbers in control mice. Most notably, rapamycin restored the potential of $\mathrm{Flk}-2^{-} \mathrm{Sca}-1^{+} \mathrm{Lin}^{-} \mathrm{c}-\mathrm{Kit}^{+} \mathrm{CD} 48^{-}$cells isolated from
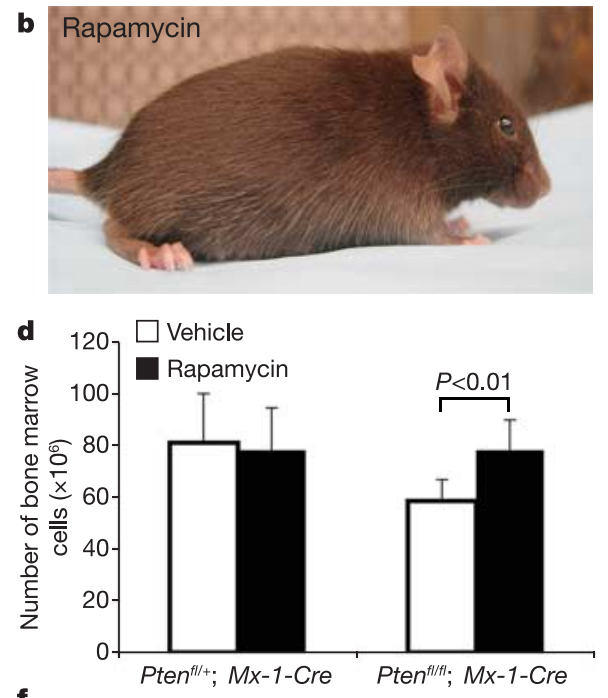

f
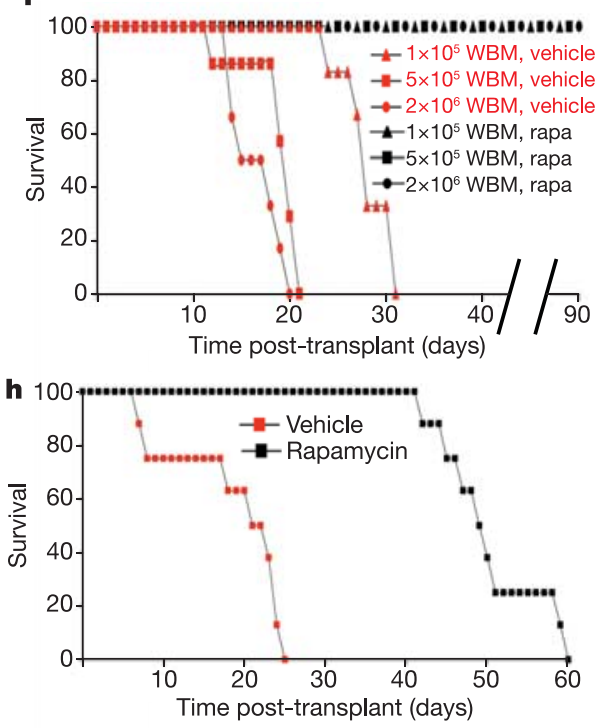

whole bone marrow (WBM) cells from these mice were transplanted into lethally irradiated recipients along with $2 \times 10^{5}$ recipient $(\mathrm{CD} 45.1)$ bone marrow cells. Recipients of bone marrow from vehicle-treated mice died with leukaemia, whereas recipients of marrow from rapamycin-treated mice remained healthy. $\mathbf{g}$, Similar donor mice were treated for five weeks with vehicle or rapamycin ( $4 \mathrm{mg}$ per $\mathrm{kg}$ per day) beginning 15 weeks after $\mathrm{pIpC}$ treatment. Nearly all recipients of bone marrow from vehicle-treated mice died of leukaemia in a dose-dependent manner, whereas recipients of cells from rapamycin-treated mice usually survived. h, Finally, $2 \times 10^{6}$ donor (CD45.2) bone marrow cells from a Pten ${ }^{f l f l} ; \mathrm{Mx}$-1-Cre mouse with AML and ALL were transplanted into sublethally irradiated recipients. The recipients were treated with vehicle or rapamycin $(0.4 \mathrm{mg}$ per $\mathrm{kg}$ per day). Panels $f$ and $\mathbf{h}$ show one representative experiment out of three. 
$\mathrm{Pten}^{f l f f} ; \mathrm{Mx}$-1-Cre mice to provide long-term multilineage reconstitution seven days after pIpC treatment (Fig. 6d, e). This confirms that Flk- ${ }^{-} \mathrm{Sca}_{-1}{ }^{+} \mathrm{Lin}^{-} \mathrm{c}^{\mathrm{K}} \mathrm{Kit}^{+} \mathrm{CD} 48^{-}$cells from Pten ${ }^{\text {fl/fl }} ; \mathrm{Mx}$-1-Cre mice are HSCs, and that rapamycin restores normal function to these cells.

The mechanism responsible for the depletion of Pten-deficient HSCs remains to be elucidated. One possibility is that persistent activation of the $\mathrm{PI}(3) \mathrm{K}$ pathway following the loss of Pten leads to reduced HSC self-renewal via a gradual increase in the rate at which HSCs exit the stem cell pool. Another possibility is that Pten deficiency induces the gradual senescence of HSCs. Conditional deletion of Pten leads to a p53-dependent senescence of prostate cells $^{36}$. Leukaemias might acquire secondary mutations that inactivate the senescence response.
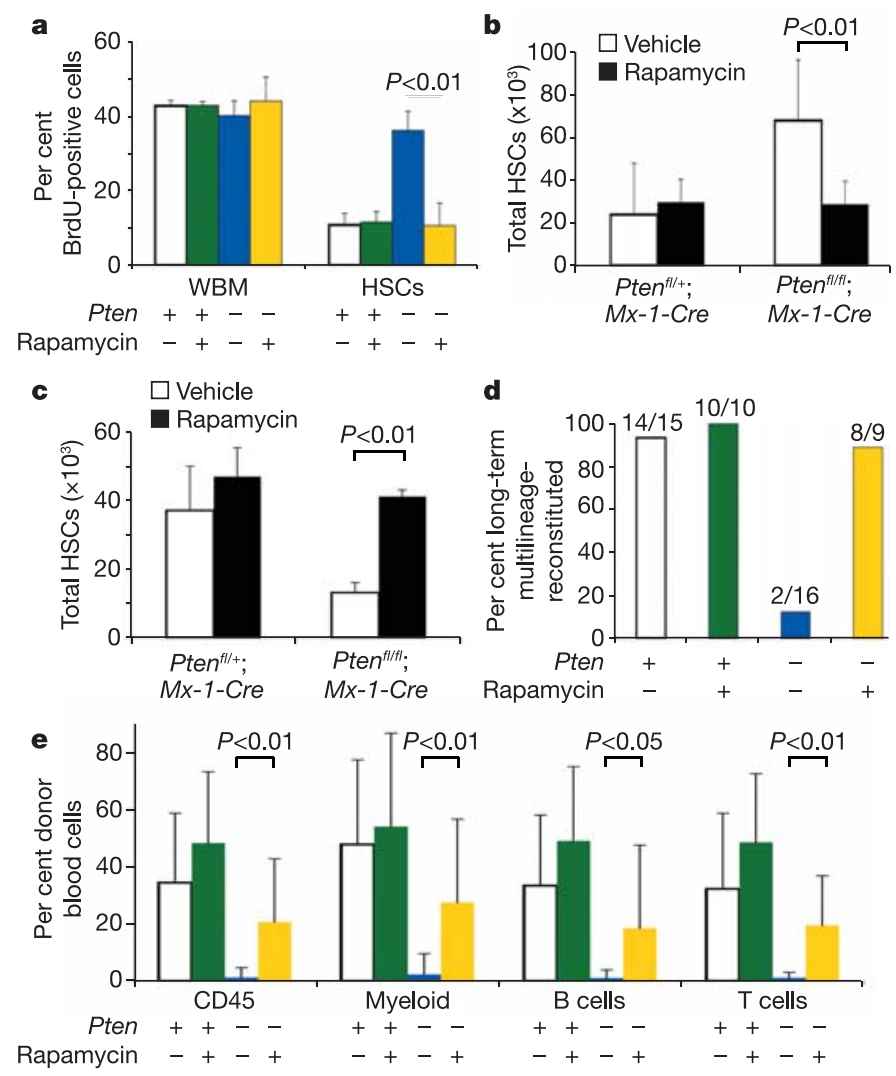

Figure 6 | Rapamycin rescues normal HSC function after Pten deletion. a, Seven days of rapamycin ( $4 \mathrm{mg}$ per $\mathrm{kg}$ per day) did not affect proliferation in whole bone marrow (WBM; 19-h pulse with BrdU), but did eliminate the increase in Flk- ${ }^{-} \mathrm{Sca}-1^{+} \mathrm{Lin}^{-} \mathrm{c}-\mathrm{Kit}^{+} \mathrm{CD} 48^{-}$HSC proliferation in $\mathrm{Pten}^{\text {flfl }}$; Mx-1-Cre mice without affecting proliferation in controls. Values are mean \pm s.d. of three experiments. b, Rapamycin eliminated the HSC expansion observed seven days after $\mathrm{pIpC}$ treatment in Pten $^{\text {fl/fl }}$;Mx-1-Cre mice without affecting HSCs in Pten ${ }^{\text {fl/ }} ; M x-1-C r e$ controls. Values are mean \pm s.d. of 6 to 7 mice per treatment. c, Rapamycin eliminated the depletion of HSCs observed 3 to 4 weeks after pIpC treatment in Pten $^{\text {fllfl }} ; M x-1-C r e$ mice without affecting controls. Values are mean \pm s.d. of three mice per treatment. d, e, Rapamycin restored the long-term $(>16$ weeks after transplantation) multilineage reconstitution potential of

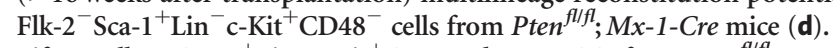
Fifteen Flk-2 ${ }^{-}$Sca- $1^{+}$Lin $^{-}$c-Kit ${ }^{+}$CD $48^{-}$donor HSCs from Pten ${ }^{\text {flffl }}$; Mx-1-Cre or control mice that had been treated with rapamycin ( $4 \mathrm{mg}$ per $\mathrm{kg}$ per day) or vehicle for seven days after $\mathrm{pIpC}$ treatment were transplanted along with 200,000 recipient bone marrow cells into irradiated recipients. Recipients received vehicle or rapamycin $(0.4 \mathrm{mg}$ per $\mathrm{kg}$ per day) starting within two weeks of transplantation. The frequency of donor white blood (CD45.2 $2^{+}$) cells, myeloid $\left(\mathrm{Mac}^{+}{ }^{+}\right)$cells, B $\left(\mathrm{B} 220^{+}\right)$cells and $\mathrm{T}\left(\mathrm{CD}^{+}\right)$cells was determined 16 to 18 weeks after transplantation $(\mathbf{e})$. Values are mean \pm s.d. of three experiments.
Deletion of the cyclin-dependent kinase inhibitor $p 21^{\text {Cipl } 1}$ also leads to HSC proliferation followed by a slow depletion ${ }^{37}$. Like PTEN, $\mathrm{p} 21^{\mathrm{CIP} 1}$ also regulates HSC quiescence. This raises the possibility that compounds that promote stem cell quiescence might consistently have different effects on normal stem cells and cancer stem cells.

Conditional Pten deletion in the fetal central nervous system increases the self-renewal and frequency of neural stem cells ${ }^{38}$. This is the opposite of what we observed, and may represent a general difference between fetal and adult stem cells rather than a difference between tissues. The balance of proto-oncogenes and tumour suppressor genes that regulate stem cell self-renewal changes between embryonic, fetal and adult life as the organogenic demand decreases and the risk of cancer increases ${ }^{11,13,39}$.

These data demonstrate that it is possible to identify-and to target therapeutically - pathways that have distinct effects on normal stem cells and cancer stem cells within the same tissue. This is an important finding, because it has been proposed that oncogenic mutations confer self-renewal potential by activating pathways used by normal stem cells, irrespective of whether the mutations occur in stem cells or other cells ${ }^{1,2,12}$. By comparing the mechanisms that regulate the maintenance of normal stem cells versus cancer stem cells, it should be possible to design new therapies and to improve existing therapies.

\section{METHODS}

Mice. Mice were housed in the Unit for Laboratory Animal Medicine at the University of Michigan. Pten ${ }^{f l+}$ and Mx-1-Cre mice were backcrossed for eight and six generations, respectively, onto a C57BL/Ka-CD45.2:Thy-1.1 background. Recipients in reconstitution assays were adult C57BL/Ka-CD45.1:Thy-1.2 mice. Flow cytometry and isolation of HSCs. Bone marrow cells were flushed from the long bones (tibias and femurs) with Hank's buffered salt solution without calcium or magnesium, supplemented with $2 \%$ heat-inactivated calf serum $\left(\mathrm{HBSS}^{+}\right.$; GIBCO). Cells were triturated and filtered through nylon screen $(45 \mu \mathrm{m}$; Sefar America) to obtain a single-cell suspension. Flk- $2^{-} \mathrm{Sca}-1^{+} \mathrm{Lin}^{-} \mathrm{c}-\mathrm{Kit}^{+} \mathrm{CD} 48^{-}$ HSCs and Thy- $1.1^{\text {low }} \mathrm{Sca}-1^{+} \mathrm{Mac}-1^{\text {low }} \mathrm{CD} 4^{\text {low }} \mathrm{B} 220^{-}$multipotent progenitors (MPPs) were isolated as previously described ${ }^{25,26,40}$. For isolation of Flk-2 ${ }^{-} \mathrm{Sca}-$ $1^{+} \mathrm{Lin}^{-} \mathrm{c}-\mathrm{Kit}^{+} \mathrm{CD} 48^{-} \mathrm{HSCs}$, whole bone marrow cells were incubated with unconjugated monoclonal antibodies to lineage (Lin) markers including B220 (6B2), CD3 (KT31.1), CD4 (GK1.5), CD5 (53-7.3), CD8 (53-6.7), Gr-1 (8C5), Mac-1 (M1/70) and Ter119. After washing, cells were resuspended in anti-rat IgG conjugated to phycoerythrin (PE; Jackson ImmunoResearch). Cells were then stained with directly conjugated antibodies to Sca-1 (Ly6A/E-APC), c-Kit (2B8-biotin), Flk-2 (A2F10-PE; eBioscience) and CD48 (HM48-1-FITC; BD Pharmingen). To identify CD45.2 ${ }^{+}$HSCs, antibodies to CD45.2 (104-FITC; BD Pharmingen) and CD48 (HM48-1-PE; eBioscience) were used. HSCs were often pre-enriched by selecting $\mathrm{c}-\mathrm{Kit}^{+}$cells using paramagnetic microbeads and autoMACS (Miltenyi Biotec). To identify leukaemic blast cells, anti-CD45 (30-F11-APC; eBioscience) was used.

The total number of Flk- $2^{-} \mathrm{Sca}-1^{+} \mathrm{Lin}^{-} \mathrm{c}-\mathrm{Kit}^{+} \mathrm{CD} 48^{-}$cells per mouse was calculated based on the frequency of this population in the bone marrow and spleen, the cellularity of the spleen and long bones, and by assuming that $15 \%$ of all bone marrow is within the long bones ${ }^{41}$. The blood and other tissues do not contribute significantly to the overall size of the HSC pool.

Long-term competitive reconstitution assays. Adult recipient mice were irradiated with an Orthovoltage X-ray source delivering $300 \mathrm{rad} \mathrm{min}^{-1}$. Recipient mice received two doses of 540 rads each, delivered $3 \mathrm{~h}$ apart. For sublethal irradiation, mice were administered one dose of 800 rads. Donor $\left(C D 45.2^{+}\right)$ HSCs were sorted and then re-sorted (for purity) into individual wells of a 96well plate containing 200,000 CD45.1 ${ }^{+}$whole bone marrow cells in $\mathrm{HBSS}^{+}$. The contents of individual wells were injected into the retro-orbital venous sinus of irradiated CD $45.1^{+}$recipients. For at least 16 weeks after transplantation, blood was obtained from the tail veins of recipient mice, subjected to ammonium chloride/potassium bicarbonate red-cell lysis, and stained with directly conjugated antibodies to CD45.2 (104-FITC), B220 (6B2), Mac-1 (M1/70), CD3 (KT31.1) and Gr-1 (8C5) to assess donor cell engraftment. Cell cycle analysis was conducted as described in Supplementary Methods.

Administration of $\mathrm{pIpC}$ and rapamycin. As described previously ${ }^{42}$, polyinosinepolycytidine (pIpC; Sigma) was resuspended in Dulbecco's-PBS at $2 \mathrm{mg} \mathrm{ml}^{-1}$ and passed through a $0.22-\mu \mathrm{m}$ filter. Mice received $25 \mu \mathrm{g}$ of $\mathrm{pIpC}$ per gram of body mass every other day for two weeks. Rapamycin (Calbiochem and LC Laboratories) was administered by intraperitoneal injection at the indicated 
doses. It was reconstituted in absolute ethanol at $10 \mathrm{mg} \mathrm{ml}^{-1}$ or $1 \mathrm{mg} \mathrm{ml}^{-1}$ and diluted in 5\% Tween-80 (Sigma) and 5\% PEG-400 (Hampton Research) before injection. The final volume of all injections was $200 \mu \mathrm{l}$.

\section{Received 1 October 2005; accepted 1 March 2006}

\section{Published online 5 April 2006.}

1. Reya, T., Morrison, S. J., Clarke, M. F. \& Weissman, I. L. Stem cells, cancer, and cancer stem cells. Nature 414, 105-111 (2001).

2. Pardal, R., Clarke, M. F. \& Morrison, S. J. Applying the principles of stem-cell biology to cancer. Nature Rev. Cancer 3, 895-902 (2003).

3. Al-Hajj, M., Wicha, M. S., Benito-Hernandez, A., Morrison, S. J. \& Clarke, M. F. Prospective identification of tumorigenic breast cancer cells. Proc. Natl Acad. Sci. USA 100, 3983-3988 (2003).

4. Singh, S. K. et al. Identification of a cancer stem cell in human brain tumors. Cancer Res. 63, 5821-5828 (2003).

5. Lapidot, T. et al. A cell initiating human acute myeloid leukemia after transplantation into SCID mice. Nature 17, 645-648 (1994).

6. Bonnet, D. \& Dick, J. E. Human acute myeloid leukemia is organized as a hierarchy that originates from a primitive hematopoietic cell. Nature Med. 3, 730-737 (1997)

7. Warner, J. K., Wang, J. C., Hope, K. J., Jin, L. \& Dick, J. E. Concepts of human leukemic development. Oncogene 23, 7164-7177 (2004).

8. Park, I.-K. et al. Bmi-1 is required for the maintenance of adult self-renewing haematopoietic stem cells. Nature 423, 302-305 (2003).

9. Lessard, J. \& Sauvageau, G. Bmi-1 determines the proliferative capacity of normal and leukaemic stem cells. Nature 423, 255-260 (2003).

10. Hemmati, H. D. et al. Cancerous stem cells can arise from pediatric brain tumors. Proc. Natl Acad. Sci. USA 100, 15178-15183 (2003).

11. Molofsky, A. V., Pardal, R. \& Morrison, S. J. Diverse mechanisms regulate stem cell self-renewal. Curr. Opin. Cell Biol. 16, 700-707 (2004).

12. Taipale, J. \& Beachy, P. A. The Hedgehog and Wnt signalling pathways in cancer. Nature 411, 349-354 (2001)

13. Molofsky, A. V. et al. Bmi-1 promotes neural stem cell self-renewal and neural development but not mouse growth and survival by repressing the p16 $6^{\text {Ink } 4 a}$ and p19 Arf senescence pathways. Genes Dev. 19, 1432-1437 (2005).

14. Lowe, S. W. \& Sherr, C. J. Tumor suppression by Ink4a-Arf: progress and puzzles. Curr. Opin. Genet. Dev. 13, 77-83 (2003).

15. Maehama, T. \& Dixon, J. E. The tumor suppressor, PTEN/MMAC1, dephosphorylates the lipid second messenger, phosphatidylinositol 3,4,5trisphosphate. J. Biol. Chem. 273, 13375-13378 (1998).

16. Stiles, B., Groszer, M., Wang, S., Jiao, J. \& Wu, H. PTENless means more. Dev. Biol. 273, 175-184 (2004).

17. Di Cristofano, A. \& Pandolfi, P. P. The multiple roles of PTEN in tumor suppression. Cell 100, 387-390 (2000).

18. Aggerholm, A., Gronbaek, K., Guldberg, P. \& Hokland, P. Mutational analysis of the tumour suppressor gene MMAC1/PTEN in malignant myeloid disorders. Eur. J. Haematol. 65, 109-113 (2000).

19. Roman-Gomez, J. et al. Promoter hypermethylation of cancer-related genes: a strong independent prognostic factor in acute lymphoblastic leukemia. Blood 104, 2492-2498 (2004).

20. Dahia, P. L. et al. PTEN is inversely correlated with the cell survival factor $\mathrm{Akt} / \mathrm{PKB}$ and is inactivated via multiple mechanisms in haematological malignancies. Hum. Mol. Genet. 8, 185-193 (1999).

21. Cheong, J. W. et al. Phosphatase and tensin homologue phosphorylation in the C-terminal regulatory domain is frequently observed in acute myeloid leukaemia and associated with poor clinical outcome. Br. J. Haematol. 122, 454-456 (2003).

22. Hock, H. et al. Tel/Etv6 is an essential and selective regulator of adult hematopoietic stem cell survival. Genes Dev. 18, 2336-2341 (2004).

23. Kühn, R., Schwenk, F., Aguet, M. \& Rajewsky, K. Inducible gene targeting in mice. Science 269, 1427-1429 (1995).

24. Kogan, S. C. et al. Bethesda proposals for classification of nonlymphoid hematopoietic neoplasms in mice. Blood 100, 238-245 (2002).

25. Christensen, J. L. \& Weissman, I. L. Flk-2 is a marker in hematopoietic stem cell differentiation: a simple method to isolate long-term stem cells. Proc. Natl Acad. Sci. USA 98, 14541-14546 (2001).
26. Kiel, M. J., Yilmaz, O. H. Iwashita, T., Terhorst, C. \& Morrison, S. J. SLAM family receptors distinguish hematopoietic stem and progenitor cells and reveal endothelial niches for stem cells. Cell 121, 1109-1121 (2005).

27. Yilmaz, O. H., Kiel, M. J. \& Morrison, S. J. SLAM family markers are conserved among hematopoietic stem cells from old and reconstituted mice and markedly increase their purity. Blood 107, 924-930 (2005).

28. Smith, L. G., Weissman, I. L. \& Heimfeld, S. Clonal analysis of hematopoietic stem-cell differentiation in vivo. Proc. Natl Acad. Sci. USA 88, 2788-2792 (1991).

29. Majumder, P. K. et al. mTOR inhibition reverses Akt-dependent prostate intraepithelial neoplasia through regulation of apoptotic and HIF-1-dependent pathways. Nature Med. 10, 594-601 (2004).

30. Inoki, K., Corradetti, M. N. \& Guan, K. L. Dysregulation of the TSC-mTOR pathway in human disease. Nature Genet. 37, 19-24 (2005).

31. Podsypanina, K. et al. An inhibitor of mTOR reduces neoplasia and normalizes p70/S6 kinase activity in Pten ${ }^{+/-}$mice. Proc. Natl Acad. Sci. USA 98, 10320-10325 (2001).

32. Neshat, M. S. et al. Enhanced sensitivity of PTEN-deficient tumors to inhibition of FRAP/mTOR. Proc. Natl Acad. Sci. USA 98, 10314-10319 (2001).

33. Recher, $C$. et al. Antileukemic activity of rapamycin in acute myeloid leukemia. Blood 105, 2527-2534 (2005).

34. Avellino, R. et al. Rapamycin stimulates apoptosis of childhood acute lymphoblastic leukemia cells. Blood 106, 1400-1406 (2005).

35. Teachey, D. T. et al. The mTOR inhibitor CCl-779 induces apoptosis and inhibits growth in preclinical models of primary adult human ALL. Blood 107, 1149-1155 (2006).

36. Chen, Z. et al. Crucial role of p53-dependent cellular senescence in suppression of Pten-deficient tumorigenesis. Nature 436, 725-730 (2005).

37. Cheng, T. et al. Hematopoietic stem cell quiescence maintained by p21cip1/waf1. Science 287, 1804-1808 (2000).

38. Groszer, M. et al. Negative regulation of neural stem/progenitor cell proliferation by the Pten tumor suppressor gene in vivo. Science 294 , 2186-2189 (2001).

39. Molofsky, A. V. et al. Bmi-1 dependence distinguishes neural stem cell selfrenewal from progenitor proliferation. Nature 425, 962-967 (2003).

40. Morrison, S. J. \& Weissman, I. L. The long-term repopulating subset of hematopoietic stem cells is deterministic and isolatable by phenotype. Immunity 1, 661-673 (1994).

41. Smith, L. H. \& Clayton, M. L. Distribution of injected 59Fe in mice. Exp. Hematol. 20, 82-86 (1970).

42. Mikkola, H. K. et al. Haematopoietic stem cells retain long-term repopulating activity and multipotency in the absence of stem-cell leukaemia SCL/tal-1 gene. Nature 421, 547-551 (2003)

Supplementary Information is linked to the online version of the paper at www.nature.com/nature.

Acknowledgements This work was supported by the Howard Hughes Medical Institute. O.H.Y. was supported by a predoctoral fellowship from the University of Michigan (UM) Institute of Gerontology. We thank the UM Flow-cytometry Core Facility, which was supported by the UM-Comprehensive Cancer Center. We also thank E. Smith in the Hybridoma Core Facility for antibody production, supported in part through the Rheumatic Disease Core Center; A. Burgess and N. McAnsh of the UM Comprehensive Cancer Center Tissue Core; and C. Mountford for excellent mouse colony management.

Author Contributions O.H.Y. performed all experiments and participated in the design and interpretation of experiments. R.V. performed all pathology on the mice with help from O.H.Y. B.K.T. and D.O.F. performed spectral karyotype analysis with help from O.H.Y. W.G. and H.W. provided the Pten ${ }^{f l / f l}$ mice and discussed pre-publication results. S.J.M. participated in the design and interpretation of experiments, and wrote the paper with O.H.Y.

Author Information Reprints and permissions information is available at npg.nature.com/reprintsandpermissions. The authors declare no competing financial interests. Correspondence and requests for materials should be addressed to S.J.M. (seanjm@umich.edu). 